\title{
DISKURSUS AGAMA DALAM RUANG PUBLIK MENURUT JÜRGEN HABERMAS
}

\author{
Leo Agung Srie Gunawan \& Nathanio Chris Maranatha Bangun*
}

\begin{abstract}
Today, the role of religions still exists in the public sphere. Habermas sees that religious citizens tend to give their aspirations in the public sphere in a destructive way. As a result, A religion is considered the cause of crime. Actually, It has a various positive benefits to be brought into the public sphere. Therefore, they can convey aspirations in a more appropriate way, namely through a religious discourse. The religious discourse is an act of discourse, that is a discussion with arguments to reach a rational consensus of the best arguments, in the realm of religion. It involves the religious, the secular, and the citizens. It also faces several challenges such as religious fundamentalism, religious privatization, and political religiofication, but it is very relevant to Indonesia, which has many religions and belief streams. Particularly, it is important to see how the relationship between religion and state in Indonesia in order to should be realized.
\end{abstract}

Kata-Kata Kunci: Diskursus agama, ruang publik, teori tindakan komunikatif, ide penterjemahan, agama dan negara, Indonesia dan Pancasila.

Pandangan Habermas terhadap agama berkembang seiring waktu. Awalnya Habermas sependapat dengan tesis sekularisasi. Dia berpendapat bahwa otoritas agama akan diganti dengan otoritas konsensus rasional. Seiring waktu Habermas berpendapat bahwa sekularisasi kehilangan kekuatannya. Kini agama perlu dikomunikasikan dengan tepat lewat diskursus agama. Diskursus adalah proses diskusi yang mempertemukan partisipan dengan argumen-argumennya masingmasing untuk mencapai konsensus. Diskursus berakhir apabila telah

\footnotetext{
* Leo Agung Srie Gunawan, lisensiat dalam bidang ilmu filsafat; lulusan Universitas Gregoriana, Roma; dosen Filsafat pada Fakultas Filsafat Unika St. Thomas, Sumatera Utara dan Nathanio Chris Maranatha Bangun Mahasiswa Post S1 Sekolah Tinggi Filsafat Teologi St. Yohanes Pematangsiantar, Sumatera Utara.
} 
terjadi kesepakatan lewat kekuatan argumen yang lebih baik. Diskursus agama merupakan salah satu bentuk diskursus dalam ranah agama. ${ }^{1}$

Habermas melihat bahwa tanpa diskursus agama, warga religius akan mengembangkan potensi destruktif dari agamanya. Di samping itu, diskursus agama juga dapat mengkomunikasikan nilai-nilai positif yang dimiliki oleh agama. Ada syarat-syarat tertentu yang harus dipenuhi oleh setiap pihak yang ikut dalam diskursus agama, agar diskursus agama berlangsung dengan baik. Pandangan ini membuka cakrawala baru mengenai bagaimana seharusnya agama menyampaikan ide ajarannya kepada masyarakat luas, baik kepada penganut agama lain, warga sekular, dan negara. ${ }^{2}$

\section{Seputar Jürgen Habermas}

Habermas lahir pada tanggal 18 Juni 1929 di Kota Düsseldorf, Jerman. Dia belajar filsafat, sejarah, sastra Jerman, psikologi, dan ekonomi di Göttingen. Setelah beberapa waktu di Zürich, dia meneruskan studi filsafat di Universitas Bonn, tempat dia mendapat gelar doktor filsafat pada tahun 1954. Disertasinya adalah Das Absolute und die Geschichte (Yang Absolut dan Sejarah). Dia adalah filsuf yang menekankan pentingnya komunikasi Dalam perjalanan waktu, dia juga mempelajari politik, agama, sastra, dan seni. ${ }^{3}$

Jürgen Habermas sebagai pemikir tentang komunikasi dipengaruhi oleh pemikiran beberapa filsuf. Mereka yang mempengaruhi pemikiran Habermas adalah Karl Mark, Theodor W. Adorno dan Max Horkheimer, serta Immanuel Kant.

Menurut Marx, di dalam sistem kapitalisme terjadi kesenjangan sosial dan penindasan karena kepemilikan alat-alat produksi pribadi.

\footnotetext{
1 Jürgen Habermas, Faith and Knowledge, https://www.friedenspreis-des-deutschenuchhandels.de/sixcms/media.php/1290/2001\%20Acceptance $\% 20$ Speech\%20Juergen $\% 20$ Habermas.pdf; diakses, 20 November 2019.

2 Jürgen Habermas, "Basis Prapolitis Sebuah Negara Hukum yang Demokratis?”, dalam Paul Budi Kleden (ed.). Dialektika Sekularisasi. Judul asli: Vorpolitische Grundlagen des demokratischen Rechtsstaates? Diterjemahkan oleh Paul Budi Kleden (Yogyakarta: Lamalera, 2010), hlm. 24.

3 Franz Magnis-Suseno, "75 Tahun Jürgen Habermas", dalam Basis, (Yogyakarta), November-Desember 2004, hlm. 5.
} 
Upah buruh hanya sedikit, sedangkan keuntungan hasil produksi diambil oleh pemilik modal. Karena itu filsafat marx terarah pada emansipasi manusia. Unsur kuncinya adalah kritik untuk membangkitkan kesadaran revolusioner. Buruh industri adalah pemilik energi revolusioner yang akan mengambil alih kepemilikan alat produksi. Akhirnya, terwujudlah masyarakat yang teremansipasi. Semangat emansipasi inilah yang diwarisi Habermas dari Marx. ${ }^{4}$

Theodor W. Adorno dan Max Horkeimer adalah guru Habermas di Frankfurt yang mengajarinya tentang Teori Kritis. Teori Kritis adalah aliran filsafat yang terinspirasi dari Marx. Kritik adalah konsep utama untuk memahami Teori Kritis. Kritik ini diarahkan pada berbagai bidang kehidupan masyarakat modern yang terkesan baik-baik saja, namun memiliki banyak kontradiksi. Misalnya, bukan kebutuhan nyata manusia yang menentukan proses produksi, melainkan pengusaha menciptakan kebutuhan agar produksi bisa laku. ${ }^{5}$

Karena itu Teori Kritis ingin membuat emansipasi. Namun Teori Kritis mencapai kebuntuan. Hal itu terjadi karena Teori Kritis tetap bertolak pada pengandaian filosofis Marx, yakni paradigma kerja manusia. Karena bekerja selalu berarti "menguasai", maka kritik yang adalah pekerjaan untuk pembebasan itu pun akan selalu menguasai dan menghasilkan perbudakan baru. Kebebasan manusia hilang karena hubungan manusia dimengerti sebagai relasi subjek-objek. Kritik adalah rasionalitas yang menyembunyikan kekuasaan. Habermas merekonstruksi Teori Kritis di kemudian hari. ${ }^{6}$

Immanuel Kant tidak merumuskan norma-norma tertentu. Dia merumuskan sebuah prosedur untuk mengecek apakah sebuah norma memiliki daya ikat moral secara universal. Prosedurnya adalah masingmasing orang wajib mengecek apakah dirinya sendiri menghendaki keberlakuan norma tersebut. Universalitas norma dilihat dari kesadaran individual masing-masing. ${ }^{7}$

\footnotetext{
${ }^{4}$ Franz Magnis-Suseno, Filsafat sebagai ..., hlm. 155.

${ }^{5}$ James Gordon Finlayson, Habermas ..., hlm. iii.

${ }^{6}$ Jürgen Habermas, Between Naturalism ..., hlm. 21.

${ }^{7}$ Franz Magnis-Suseno, 12 Tokoh Etika ..., hlm. 224.
} 


\section{Pemikiran tentang Komunikasi}

Habermas merekonstruksi Teori Kritis. Habermas berpendapat bahwa Teori Kritis tidak boleh lagi didasarkan oleh paradigma kerja yang bersifat monolog. Paradigma ini tidak cocok untuk situasi masyarakat yang plural. Karena itu Teori Kritis harus didasarkan oleh paradigma komunikasi. Paradigma komunikasi terjadi dalam hubungan subjek-subjek. Karena itu Teori Kritis berubah menjadi Teori Tindakan Komunikatif. Komunikasi terjadi bukan melalui hubungan kekuasaan, melainkan lewat pengakuan akan kebebasan dan kepercayaan keduabelah pihak yang berkomunikasi. Paradigma ini menghargai otonomi pihak lain. Paradigma ini bersifat rasional dan dialogis karena para subjek yang berkomunikasi senantiasa mengarahkan diri pada pencapaian pemahaman satu sama lain. Emansipasi diperoleh bukan dengan jalan revolusioner Marx untuk mencapai masyarakat yang diimpikan, melainkan dengan komunikasi yang tepat untuk mencapai konsensus. ${ }^{8}$

Pemikiran Habermas selanjutnya adalah soal diskursus. Diskursus adalah sebuah proses diskusi yang bertujuan untuk mencapai kesepakatan lewat argumen-argumen partisipan yang berkomunikasi. Konsensus dicapai lewat argumentasi yang lebih baik. Sekalipun diskursus telah mencapai konsensus, konsensus tersebut bersifat sementara. Di kemudian hari, informasi baru dapat mengalahkan konsensus lama. Karena itu proses diskursus yang baru harus dilakukan kembali. $^{9}$

Ada peraturan-peraturan diskursus yang harus diikuti. Pertama, setiap orang yang bisa bicara dan bertindak boleh ikut dalam diskursus. Kedua, setiap peserta boleh mempersoalkan setiap pernyataan. Ketiga, setiap peserta boleh memasukkan pernyataannya ke dalam diskursus. Keempat, tidak seorangpun peserta boleh dihalangi melaksanakan hak-haknya di atas. ${ }^{10}$

\footnotetext{
${ }^{8}$ Gusti A. B. Menoh, Agama dalam ..., hlm. 52- 53.

${ }^{9}$ Andrew Edgar, Habermas ..., hlm. 42-43.

${ }^{10}$ Andrew Edgar, Habermas ..., hlm. 42-43.
} 
Dalam diskursus, para partisipan membuat argumen dengan memenuhi syarat "klaim-klaim keabsahan" (validity claim). Klaim keabsahan adalah komitmen yang dibuat oleh para pembicara untuk membela apa yang mereka katakan dan apa yang mereka lakukan. Ada tiga macam klaim kesahihan, yakni kebenaran (truth), kejelasan (clarity) dan kejujuran (sincerity). Klaim kebenaran berarti kebenaran isi pernyataan pembicara. Klaim kejelasan berarti kesamaan makna yang ditangkap pendengar dengan yang dikatakan pembicara. Klaim kejujuran berarti keselarasan antara makna yang dikatakan dengan maksud pembicara. $^{11}$

Lebih jauh, diskursus diterapkan ke dalam bidang moral lewat etika diskursus. Etika diskursus bukanlah sebuah pendasaran etika. Etika ini tidak menghasilkan jawaban siap pakai atas pertanyaan-pertanyaan moral. Etika ini adalah metode untuk memastikan kembali arti normanorma moral yang dipertanyakan. Ada dua prinsip etika diskursus yakni prinsip universalisasi (U) dan prinsip diskursus (D). Prinsip U berakar dari pemikiran Kant, yang berpendapat bahwa prinsip moral hanya dapat diterima bila semua orang setuju untuk terikat di dalamnya. Di sisi lain, metode Kant kurang memadai karena universalitas sebuah norma tidak dapat tergantung dari kesadaran individual saja. Metode Kant tidak mengizinkan orang-orang untuk berkomunikasi satu sama lain, sehingga bersifat isolatif dan monolog. Karena itu prinsip D mengatakan bahwa validitas normatif diterima lewat diskursus rasional, bukan hanya lewat kesadaran individual. $^{12}$

Habermas menerapkan diskursus pada wilayah politik lewat teori demokrasi deliberatif. Demokrasi deliberatif adalah demokrasi tempat legitimasi hukum tercapai karena lahir dari diskursus-diskursus dalam masyarakat sipil. Demokrasi deliberatif disebut juga demokrasi permusyawaratan. Di dalam demokrasi deliberatif, negara tidak lagi mengambil keputusan dalam ketertutupan, melainkan dalam proses diskursus yang argumentatif. Diskursus masyarakat tidak dapat

\footnotetext{
${ }^{11}$ Jürgen Habermas, Moral Consciousness ..., hlm. 103.

12 Jürgen Habermas, Moral Consciousness ..., hlm. 65-66
} 
menguasai sistem politik namun dapat mengarahkan keputusankeputusannya. ${ }^{13}$

Selain diskursus, ruang publik menjadi pemikiran Habermas. Pemikiran Ruang publik berasal dari bahasa Jerman "Öffentlichkeit", yang berarti "keadaan yang dapat diakses oleh semua orang. Keadaan dapat diakses semua orang itu membuat ruang publik tidak bersifat tunggal, melainkan terdapat di mana-mana dengan jumlah orang tidak terbatas. Ruang publik dapat dimengerti sebagai ruang masyarakat privat yang berkumpul bersama menjadi sebuah publik. Tujuan ruang publik adalah mengatasi perbedaan-perbedaan dalam berbagai kepentingan dengan mencapai konsensus yang sama lewat diskursus. ${ }^{14}$

Ruang publik merupakan suatu jaringan untuk mengkomunikasikan informasi-informasi dan pandangan-pandangan setiap orang. Karena itu ruang publik bisa tidak bersifat fisik. Aliranaliran komunikasi diproses untuk menjadi opini-opini publik. Ada dua jenis ruang publik, yaitu ruang publik formal dan ruang publik informal. Ruang publik formal berlangsung di parlemen, peradilan dan institusi negara. Ruang publik informal adalah wilayah nonpemerintahan, seperti facebook, koran, warung kopi, dan lain-lain. Ruang publik informal itu adalah arena bagi warga bergama untuk menyatakan gagasan religiusnya masing-masing. ${ }^{15}$

Diskursus dalam ruang publik tidak boleh hanya mengidentifikasi persoalan-persoalan, melainkan juga harus mentematisasi masalahmasalah tersebut, menawarkan solusi-solusi, dan mengusahakan agar opini publik dalam ruang publik informal didengar oleh pemerintah. Opini publik diharpkan dapat mempengaruhi proses pengambilan keputusan dalam pemerintahan. Opini publik akan bekerja sebagai pengawas terhadap kekuasaan negara. Apabila hasil diskursus dalam ruang publik informal tersambung dengan negara, maka hukum-hukum

\footnotetext{
13 Jürgen Habermas, Between Facts ..., hlm. 304.

${ }^{14}$ Jürgen Habermas, Between Facts ..., hlm. 360.

${ }^{15}$ Gusti A. B. Menoh, Agama dalam ..., hlm. 88.
} 
_Lea Agung Srie Gunaman \& Nathania Chris Maranatha Bangun. Diskurs Agama dalam Ruang Publik

yang dibuat oleh negara akan semakin kuat dan rakyat semakin berdaulat. $^{16}$

\section{Perkembangan Pemikiran tentang Agama}

Habermas membagi tahap-tahap pemikiran tentang agama dalam relasinya dengan ruang publik. Tahap pemikirannya ini sejalan dengan pandangan masyarakat tetang peran agama dalam kehidupan sosial dan kehidupan bernegara sebagai ruang publik; khususnya, relasi peran agama dalam relasinya dengan negara yang memiliki tanggung jawab terhadap masyarakatnya. Pertanyaannya adalah bagaimana agama akan diperankan dalam ruang publik?

Tahap pemikiran pertama adalah pelenyapan agama. Pandangan awal Habermas tentang peran sosial agama dipengaruhi oleh hipotesis sekularisasi. Hipotesis tersebut menyatakan bahwa suatu saat agama akan lenyap dari kehidupan masyarakat, karena peran akal budi akan menggantikan peran agama dalam masyarakat. Awalnya Habermas berharap agama lenyap sama sekali. Habermas berpendapat bahwa otoritas yang awalnya dimiliki oleh agama akan digantikan oleh otoritas konsensus yang berbasis argumen rasional. ${ }^{17}$

Tahap pemikiran kedua adalah privatisasi agama. Pendirian Habermas telah berubah. Menurut Habermas, pada masa ini masyarakat masih mempertahankan akar religius mereka sekalipun sekularisasi telah terjadi. Habermas kini mengganti pandangannya dari "pelenyapan agama" menjadi "privatisasi agama". Dia melihat bahwa agama dapat menawarkan penghiburan atas penderitaan manusia. Namun, warga religius sebaiknya tidak membawa keyakinan-keyakinan mereka ke dalam ranah politik. Di dalam ruang publik, bahasa sekular sudah cukup. $^{18}$

Tahap pemikiran ketiga adalah publikasi agama. Di akhir tahun 1990, Habermas mendukung publikasi terhadap agama. Dia menekankan bahwa agama seharusnya tidak dibatasi ke dalam ruang privat. Dia

\footnotetext{
${ }^{16}$ B. Hari Juliawan, "Ruang Publik Habermas ...", hlm. 38.

${ }^{17}$ Jürgen Habermas, The Theory ..., hlm. 77.

18 Philippe Portier, "Religion and ...", hlm. 426.
} 
melihat bahwa agama memiliki nilai rasional dan fungsi positif. Habermas menekankan pentingnya diskursus antara filsafat dan agama. Filsafat dapat belajar dari agama dan agama dapat belajar dari filsafat. Pemikiran Habermas pada tahap ketiga inilah yang dibahas penulis dalam skripsi ini. ${ }^{19}$

\section{Alasan-alasan untuk Berdiskursus}

Menurut Habermas, dasar diskursus filosofis antara iman dan akal budi adalah kesadaran dari nalar yang menyadari keterbatasannya dan menemukan bahwa dirinya terarah pada sesuatu yang lain. Keterbatasan tersebut menuntut akal budi mengakui kekuasaan pihak lain sehingga akal budi tidak hendak kehilangan orientasi rasionalnya dan berakhir pada jalan buntu kesombongan diri. Selain itu, Habermas melihat perkembangan dalam bioteknologi yang berujung pada instrumentalisasi manusia. Instrumentalisasi manusia ini membuat manusia saling mengobjekkan sesamanya, padahal dalam berelasi, seharusnya manusia sama-sama bertindak sebagai subjek. Habermas meragukan kemampuan akal budi manusia untuk melawan paham instrumentalisasi manusia. Habermas berpendapat bahwa Agama memiliki Kitab Suci yang memiliki nilai-nilai moral dan etika yang dapat menjadi jawaban untuk masalah tersebut. ${ }^{20}$

Sejarah menunjukkan bahwa diskursus agama telah terjadi dalam perjumpaan Kristianitas dan metafisika. Diskursus ini tidak hanya menghasilkan suatu bentuk intelektual teologi dogmatik dan helenisasi kristianitas, tetapi juga penyerapan nilai-nilai kristiani melalui filsafat. Diskursus ini menghasilkan konsep-konsep normatif seperti tanggung jawab, otonomi, pembenaran, emansipasi, dan lain-lain. Sejarah juga membuktikan bahwa ada pengaruh politik yang positif dari pergerakan warga religius, yakni mempertahankan demokrasi dan hak-hak manusia seperti yang dilakukan oleh Martin Luther King. ${ }^{21}$

\footnotetext{
19 Philippe Portier, "Religion and ...", hlm. 427.

20 A. Sunarko, "Dialog Teologis ...", hlm. 108-109.

${ }^{21}$ Jürgen Habermas, “Basis Prapolitis ...”, hlm. 21-22.
} 
Habermas melihat sebuah fenomena melemahnya solidaritas manusia karena dinamika ekonomi yang tak dapat dikendalikan secara demokratis sehingga para warga menjadi subjek-subjek yang terpisah, yang bertindak atas dasar kepentingan sendiri dan memanfaatkan hak-hak subjektifnya untuk saling melawan. Akibatnya, privatisme warga negara semakin kuat karena hilangnya peran pembentukan pendapat dan kehendak bersama secara demokratis. ${ }^{22}$ Habermas melihat bahwa agama memiliki potensi untuk memperkuat solidaritas manusia. Potensi agama untuk membangun solidaritas terdapat pada kesadaran sebagai suatu kelompok yang diperkuat oleh ritus atau kegiatan keagamaan yang melibatkan semua warga beragama. ${ }^{23}$

Diskursus juga penting agar semua warga masyarakat, yang terdiri dari beragam pandangan hidup dan agama, dapat dengan setara melaksanakan aktivitas politik. Potensi konflik yang ada karena perbedaan pada tataran kognitif dapat diminimalisir dengan berlakunya prinsip diskursus agama. $^{24}$

\section{Tanggapan Habermas terhadap Pandangan filsuf mengenai Agama}

Habermas menanggapi pandangan dari empat filsuf mengenai agama. Pertama, John Rawls mengakui semua bentuk doktrin moral atau teori politik yang rasional, baik religius maupun non-religius, sejauh doktrin tersebut menerima klausul kondisional. Hal ini penting karena hanya argumentasi sekular yang berlaku pada tataran ruang publik formal dan informal. ${ }^{25}$

Kedua, menurut Weithmann, warga religius memiliki hak untuk membela pandangan politik mereka dalam konteks doktrin religius. Untuk itu, mereka perlu memenuhi dua kriteria. Pertama, mereka harus diyakinkan bahwa pemerintahan secara sah dapat melaksanakan hukum atau kebijakan yang mereka dukung dengan argumen religius. Kedua, mereka harus bersedia menyatakan mengapa mereka mempercayai

\footnotetext{
${ }^{22}$ Giancarlo Bosetti, "Pemikiran untuk ...", hlm. 17-18.

${ }^{23}$ A. Sunarko, "Dialog Teologis ...", hlm. 85-86.

${ }^{24}$ Jürgen Habermas, Between Naturalism..., hlm. 125.

${ }^{25}$ Franz Magnis-Suseno, “75 Tahun..., hlm. 9.
} 
doktrin religius mereka. Ketiga, menurut Robert Audi, negara tidak dapat mengharapkan semua masyarakat untuk memberikan pernyataan politis mereka yang terpisah dari keyakinan religius. Pembatasan ini hanya tepat bagi para politisi, karena mereka memiliki tugas yang bersifat netral di dalam institusi negara. ${ }^{26}$

Keempat, menurut Nicholas Wolterstorff, warga religius seharusnya diperkenankan berargumentasi dengan bahasa religius tidak hanya pada tataran ruang publik informal, tetapi juga dalam ruang publik formal. Para pembuat keputusan politis dalam ruang publik formal diperkenankan membuat keputusan atas dasar argumen-argumen religius dan kesepakatan dicapai melalui voting. Dia berpendapat bahwa dominasi mayoritas dalam masyarakat yang memiliki beragam ideologi merupakan dasar yang baik. ${ }^{27}$

Menurut Habermas, ada kemungkinan pandangan Wolterstoff membuat hukum hanya akan diberlakukan atas dasar kepercayaan mayoritas religius yang berkuasa karena keputusan dicapai melalui voting. Hal yang tidak legitim bukan voting mayoritas, melainkan pelanggaran terhadap komponen inti dari prosedur demokrasi, yakni kodrat diskursif deliberatif yang mendahului voting. Hal lainnya yang tidak legitim dari pandangan Wolterstoff adalah pelanggaran terhadap prinsip netralitas, yakni hukum seharusnya dirumuskan dalam bahasa yang dapat dimengerti oleh semua masyarakat. Hal tersebut dapat membuat kelompok mayoritas melakukan represi kepada kaum minoritas sehingga mengancam solidaritas. ${ }^{28}$

Di satu sisi, Habermas setuju kepada Rawls bahwa warga religius dapat memberikan sumbangan dalam diskursus publik dengan syarat menerjemahkan bahasa religius mereka ke dalam bahasa sekular agar dapat diterima secara luas. Di sisi lain, pandangan Habermas sejalan dengan Weithmann, yakni peran agama kepada masyarakat dapat lenyap bila mereka selalu harus menemukan bahasa yang bersifat universal.

\footnotetext{
${ }^{26}$ Jürgen Habermas, "Religion in the..., hlm. 8-11.

27 Jürgen Habermas, "Religion in the..., hlm. 12.

${ }^{28}$ Habermas, Between Naturalism..., hlm. 139.
} 
Habermas setuju dengan Robert Audi bahwa aturan penerjemahan hanya berlaku ketat bagi para pejabat politik. ${ }^{29}$

\section{Diskursus Agama sebagai Proses Pembentukan Sikap}

Menurut Habermas, ada tiga sikap sebagai warga sekular, warga religius, dan warga negara. Pertama, warga sekular perlu merefleksikan hubungan antara iman dan pengetahuan secara kritis. Warga sekular akan menemukan bahwa banyak konsep normatif yang terbentuk dari agamaagama. Warga sekular juga harus memberikan kesempatan kepada kaum religius untuk berpartisipasi dalam ruang publik formal dengan bahasa religius. Warga sekular tidak dapat mengabaikan suatu potensi kebenaran dalam bahasa religius. Bahkan negara dapat menuntut para warga sekular untuk secara aktif ikut berusaha menerjemahkan bahan-bahan yang berguna dari bahasa religius ke dalam bahasa yang lebih universal. ${ }^{30}$

Namun, kerja sama membutukan sikap kognitif. Kerja sama dengan warga religius tidak akan berhasil bagi mereka yang hanya melihat agama sebagai sebuah peninggalan kuno dari masyarakat pra-modern yang terus ada hingga sekarang. Warga sekular yang kembali melihat nilai-nilai agama sebagai sesuatu yang penting dapat disebut sebagai masyarakat postsekular. ${ }^{31}$

Kedua, warga Religius perlu menyadari bahwa ada ikatan-ikatan sekularisasi untuk pengetahuan, netralitas kekuasaan negara, dan kebebasan beragama bagi semua orang. Agama dituntut untuk melepaskan klaim sebagai satu-satunya pemilik otoritas untuk menafsirkan dan menentukan cara hidup yang legitim. Mereka harus berani menghadapi beragam argumen rasional yang bersifat pro dan kontra. $^{32}$

Ada tiga hal yang harus dimiliki warga religius. Pertama, warga religius harus mengembangkan sebuah sikap rasional terhadap agama lainnya dan terhadap berbagai pandangan hidup yang mereka hadapi

\footnotetext{
${ }^{29}$ Jürgen Habermas, "Religion in the..., hlm. 7.

${ }^{30}$ Jürgen Habermas, "Hal-hal yang Diakui ...”, hlm. 57-59; A. Sunarko, "Dialog Teologis ...", hlm. 79.

31 Jürgen Habermas, "Religion in the..., hlm. 15-16.

32 Jürgen Habermas, "Hal-hal yang Diakui ...”, hlm. 56.
} 
lewat diskursus. Mereka berhasil bila mampu menghubungkan keyakinan-keyakinannya dengan pandangan dari agama lain, tanpa mengorbankan klaim tentang kebenaran dari agama atau keyakinannya sendiri. Kedua, warga religius harus menyesuaikan diri dengan otoritas ilmu pengetahuan. Mereka berhasil bila mereka mampu merumuskan hubungan positif antara isi agama dengan ilmu pengetahuan, sehingga tidak terjadi pertentangan di antara keduanya. ${ }^{33}$

Ketiga, warga religius harus setuju pada premis-premis dasar negara hukum modern, bahwa yang berlaku dalam dunia politik adalah argumen-argumen sekular, sehingga dapat dimengerti semua orang. Karena itu, warga religius perlu menerjemahkan bahasa religiusnya ke dalam bahasa sekular di dalam ruang publik formal. Di sisi lain, peran agama integral dalam diri orang beriman, yakni bahwa agama hadir dalam hidup keseharian warga religius. Warga religius mendasarkan keputusan-keputusan mereka berdasarkan keyakinan religius mereka. Karena itu, warga religius harus diijinkan untuk mengekspresikan dan membela keyakinan mereka dalam bahasa religius dalam ruang publik formal bila mereka tidak menemukan terjemahan sekular untuk argumentasi religius tersebut. ${ }^{34}$

Ketiga, negara hukum demokratis perlu memberikan kebebasan berkomunikasi dan mendorong partisipasi warganya untuk ikut dalam diskursus dalam ruang publik. Negara harus bersikap netral terhadap warga sekular atau warga religius. Negara perlu menyadari bahwa ruang publik membutuhkan kehadiran agama karena agama memiliki rasionalitas tertentu. Agama dan negara harus dipisahkan. Hukum negara tidak tergantung pada legitimasi agama tertentu. Negara harus didirikan berdasarkan undang-undang yang demokratis. Prinsip pemisahan Gereja dan negara mewajibkan institusi-institusi politis untuk menentukan hukum, dekrit, dan mengukur bahasa yang cocok diakses oleh semua warga. Negara harus memberi kesempatan bagi warga religius untuk menyatakan aspirasi mereka dalam masyarakat melalui opini publik baik di dalam ruang publik formal maupun ruang publik informal. Karena itu,

\footnotetext{
33 A. Sunarko, "Dialog Teologis ...", hlm. 88-89.

34 Jürgen Habermas, "Religion in the..., hlm. 8-14; bdk. Jürgen Habermas, Between Naturalism..., hlm. 138.
} 
negara perlu membuat sebuah "filter institusional" untuk menerjemahkan opini publik yang mengandung bahasa religius. ${ }^{35}$

Dalam kaitan antara warga sekular, warga religius, dan warga negera, Habermas memberikan sebuah contoh mengenai penerjemahan bahasa religius ke dalam bahasa sekular, yakni teks Kejadian 1:27 ${ }^{36}$. Teks ini memuat dua hal, yakni manusia adalah ciptaan Allah dan sekaligus dia adalah citra Allah. "Manusia sebagai citra Allah" diterjemahkan Habermas ke dalam bahasa filsafat menjadi "Manusia adalah pribadi yang memiliki kebebasan". Allah tidak menggerakkan manusia seperti seorang teknisi. Suara Allah menggerakkan dari luar lewat moralitas. ${ }^{37}$

"Manusia sebagai ciptaan Allah" berarti manusia mengerti bahwa asal-usulnya bukan dari sesama manusia, melainkan dari sesuatu yang lain. Barangsiapa, berkat kemungkinan yang disediakan oleh bioteknologi, menempatkan diri pada posisi Allah (turut campur secara genetis dalam menciptakan manusia), maka orang tersebut, dalam bahasa Kitab Suci, "melanggar batas antara ciptaan dan Pencipta". Habermas menerjemahkannya ke dalam bahasa filsafat sebagai "manusia seperti itu merusak tatanan relasi antarmanusia yang berdasarkan kepada kebebasan yang setara". ${ }^{38}$

\section{Tantangan Diskursus Agama}

Sekalipun diskursus agama mempunyai nilai-nilai positif dalam menciptakan relasi yang harmonis antara agama dan negara, tetapi diskursus ini mempunyai tantangan-tantangan yang perlu mendapatkan perhatian. Pertama adalah fundamentalisme agama. Fundamentalisme agama adalah ketidakrelaan penganut agama untuk memperdebatkan keyakinannya yang berbeda dengan keyakinan lain. Ketidakrelaan tersebut bersumber dari klaim penganut agama bahwa kebenaran yang dimilikinya mutlak. Fudamentalisme agama dapat mengarah kepada sifat

\footnotetext{
35 Jürgen Habermas, Between Naturalism..., hlm. 122-124.

36 Isi teks Kejadian 1:27 adalah "Maka Allah menciptakan manusia itu menurut gambarNya, menurut gambar Allah diciptakan-Nya mereka".

37 Jürgen Habermas, Peace Prize..., hlm. 6.

38 A. Sunarko, "Dialog Teologis ...", hlm.109-110; bdk. Jürgen Habermas, Peace Prize..., hlm. 6.
} 
destruktif yang disertai aksi-aksi kekerasan. Menurut Habermas, fundamentalisme agama akan merusak diskursus agama karena pihak terkait hanya berpusat pada pemikirannya sendiri tanpa mau melihat sisi baik pihak lain. ${ }^{39}$ Kedua adalah privatisasi agama. Privatisasi agama yang dimaksud adalah penggunaan agama untuk penghayatan pribadi. Hal ini berbeda dari praktik komunitas agama yang pada umumnya terorganisir. Di dalam privatisasi agama, tema "Allah" dapat direduksi menjadi sarana bagi kepentingan pribadi, sehingga Allah "dilarang" mengungkapkan tuntutan-tuntutan yang mengganggu kemapanan dan kenyamanan pribadi. ${ }^{40}$ Ketiga adalah religiofikasi politik. Religiofikasi politik adalah kecenderungan untuk memberikan atribut keilahian pada dunia politik, sehingga politik bersifat mutlak. Hukum, yang sebenarnya merupakan hasil rekayasa untuk kepentingan kelompok tertentu, disebut sebagai hukum yang mutlak dari Yang Ilahi. Akibatnya, hukum tersebut harus dipatuhi semua orang. ${ }^{41}$

\section{Keunggulan Pemikiran Habermas}

Diskursus agama menciptakan komunikasi yang adil antara akal budi dan iman. Dalam diskursus agama kaum religius harus menerima otoritas akal budi dalam ilmu pengetahuan. Namun, kaum sekular juga harus melihat sisi rasional dari agama yang dapat diterjemahkan ke dalam bahasa universal. Kaum sekular juga perlu keluar dari paham saintisme. Diskursus agama merupakan tempat untuk saling bertukar argumen secara adil dan bersedia dikritisi untuk mencapai kesepakatan. Diskursus agama juga tidak menyetujui paksaan dan manipulasi, melainkan menyetujui pengungkapan ide secara bebas. ${ }^{42}$

Diskursus Agama Membentuk Etika Umum. Urgensi untuk menemukan etika umum untuk setiap tindakan semakin kuat karena kesalahan arah ilmu pengetahuan dan terorisme. Akal budi tidak bisa sendirian membentuk etika umum dan demikian pula halnya dengan

\footnotetext{
${ }^{39}$ Jürgen Habermas, "Basis Prapolitis ...”, hlm. 20-21

40 Adrianus Sunarko, "Berteologi bagi Agama di Zaman Post-Sekular" dalam Diskursus, Vol. 15 (April 2016), hlm. 26-27.

${ }^{41}$ A. Sunarko, "Dialog Teologis ...", hlm. 167-168.

42 Josef Schmidt, "A Dialogue in Which There Can Only be Winners" dalam An Awareness of What is Missing: Faith and Reason in a Post-Secular Age (USA: Polity Press, 2010), hlm. 59-63.
} 
agama. Etika umum tersebut dapat ditemukan lewat diskursus agama. Diskursus agama mengembangkan pemahaman bersama antara warga sekular dan warga religius, sehingga norma-norma dan nilai-nilai esensial yang dikenal dan dihayati oleh umat manusia dapat mempunyai kekuatan terang baru. Dengan demikian, tercipta etika umum yang dapat menjadi pegangan bersama antara kaum religius dan kaum sekular. ${ }^{43}$

Gagasan Masyarakat Postsekular. Gagasan ini berhasil membuat perluasan dari kategori "masyarakat religius" dan "masyarakat sekular". Kategori tersebut membuat peran agama menjadi sangat sempit karena agama menjadi tidak penting bagi masyarakat yang tidak melihat dirinya dalam kategori "masyarakat religius". Gagasan tersebut menunjukkan bahwa agama tetap memberikan peran penting dalam masyarakat sekular. Agama kembali disambut tanpa menolak akal budi. Karena itu, masyarakat sekular harus berusaha membangun komunikasi konstruktif dengan agama. Gagasan ini juga menunjukkan kesalahan prediksi tentang masuknya agama dalam wilayah privat. ${ }^{44}$

Ide Penerjemahan Bersifat Universal dan Bermanfaat Ganda. Ide penerjemahan bahasa religius ke dalam bahasa sekular bersifat universal karena memiliki potensi untuk mengungkapkan kebenarankebenaran dalam agama-agama. Magnus Striet menunjukkan hal itu dengan mengaitkan pandangan Habermas tentang isi Kitab Kejadian 1:47 dengan gagasan teologinya. Gagasan Habermas mengenai kebebasan harus dipahami dalam paradigma kasih Allah. Allah ingin menyelamatkan manusia berarti Dia ingin menjalani relasi kasih timbal balik dengan manusia, karena itu manusia harus bersifat bebas untuk menanggapi kasih Allah. ${ }^{45}$ Selain itu, ide penerjemahan itu bermanfaat ganda karena di satu sisi negara akan memiliki dasar hukum berdasarkan tradisi religius masyarakat setempat. Di sisi lain, warga religius semakin dinamis karena berinteraksi dengan banyak pihak.

\footnotetext{
${ }^{43}$ Joseph Ratzinger, "Nalar dan Iman..., hlm. 63.

${ }^{44}$ Andre Costa, Habermas on Religion..., hlm. 88.

45 A. Sunarko, “Dialog Teologis ...”, hlm. 107-113.
} 


\section{Kelemahan dari Pemikiran Habermas}

Kelemahan Ide Penerjemahan. Tidak semua bahasa dapat diterjemahkan ke dalam bahasa lain. Terkadang suatu kata kehilangan muatannya ketika diterjemahkan ke dalam bahasa lain. Karena itu, Habermas harus dapat menunjukkan, bahwa konsep religius yang diterjemahkan itu tetap lengkap, bukannya hilang. Miguel Vatter berpendapat bahwa apabila ide penerjemahan tersebut sukses, maka warga religius tidak akan perlu lagi menegaskan peran agama dalam masyarakat. Ide penerjemahan saja tidak cukup. Kita perlu mengerti argumen-argumen pihak lain dengan memahami orang-orangnya dan bingkai budaya yang menyertainya. Penerjemahan juga harus diikuti dengan perubahan sikap untuk mau memahami latar belakang pihak lain. ${ }^{46}$

Kelemahan Gagasan Ruang Publik. Gagasan Habermas mengenai ruang publik mengandalkan tindakan komunikasi yang setara antar anggota masyarakat dan bebas dari dominasi. Hal tersebut terkesan utopis karena masyarakat selalu bergelut dengan ketimpangan kekuasaan ekonomi, politik, dan budaya. Seringkali kelompok minoritas tidak memiliki kekuasaan yang cukup besar untuk diperhitungkan dalam ruang publik, baik informal maupun formal. ${ }^{47}$

Ruang publik juga mengandaikan para peserta yang berdiskursus mengambil konsensus berdasarkan argumentasi yang lebih baik. Padahal, debat politik tidak pernah murni rasional. Karena itu hendaknya peserta diskursus tidak usah berlebihan dalam mencoba meruntuhkan argumentasi lawan diskusi dengan meyakinkan mereka akan validitas argumentasi pribadi. Diskursus tidak akan berhasil, kecuali setiap pihak siap untuk memeriksa secara kritis ketakutan, penilaian, dan asumsiasumsi mereka. $^{48}$

\footnotetext{
46 Miguel Vatter, "Habermas between Athens and Jerusalem", dalam Interpretation Vol. 38 (2011), hlm. 243-244; bdk. Andre Costa, Habermas on Religion ...", hlm. 109.

${ }^{47}$ B. Hari Juliawan, "Ruang Publik Habermas..., hlm. 38-39.

48 B. Hari Juliawan, "Ruang Publik Habermas..., hlm. 39.
} 


\section{Relevansi bagi Masyarakat Indonesia.}

Pemikiran Habermas terkait diskursus agama dalam ruang publik yang relevan di Indonesia adalah sikap saling belajar antar warga religius, hubungan antara agama dengan negara dan demokrasi deliberatif. Sikap saling belajar antar warga religius telah terjadi sejak Indonesia hendak merumuskan dasar negaranya. Para pendiri bangsa Indonesia membuat sebuah konsensus dalam sila pertama Pancasila yang isinya "Ketuhanan Yang Maha Esa", untuk menjembatani pluralisme agama di Indonesia. ${ }^{49}$ Selanjutnya, para penganut agama yang di Indonesia perlu membangun sikap kognitif bagi, yakni warga beragama harus mengembangkan sebuah sikap rasional terhadap agama dan aliran kepercayaan lain lewat diskursus. Sikap ini bisa dikatakan berhasil bila warga beragama mampu menunjukkan kaitan antara pandangan-pandangan religiusnya dengan pandangan dari agama dan keyakinan lain, tanpa mengorbankan klaim tentang kebenaran agamanya sendiri. Misalnya, usaha yang dilakukan oleh komisi HAK (Hubungan antara agama dan kepercayaan) terkait dialog lintas agama untuk melakukan kerja sama di bidang kemanusiaan. ${ }^{50}$

Pemikiran Habermas yang relevan dengan Indonesia selanjutnya berkaitan dengan demokrasi deliberatif. Indonesia adalah negara berbasis demokrasi. Hal ini tercantum dalam sila keempat. Dalam model demokrasi deliberatif, keputusan berdasarkan voting suara mayoritas hanyalah salah satu syarat. Model demokrasi ini adalah warisan berharga untuk menghadapi masalah terkait relasi antar agama mayoritas dan minoritas di Indonesia. Negara hukum demokratis legitim apabila negara tersebut terkoneksi dengan ruang publik. Karena itu, Indonesia tidak boleh mengesampingkan aspirasi-aspirasi publik dari demonstrasi, facebookers, forum-forum perjuangan, dan lain-lain. Indonesia perlu memaksimalkan peran ruang publik, khususnya ruang publik informal, agar keputusan-keputusan negara semakin rasional. Masyarakat Indonesia juga harus memegang prinsip bahwa argumen yang berlaku di dalam ruang publik formal adalah argumen sekular. Semua pihak yang

\footnotetext{
${ }^{49}$ Redemptus Gora, "Melacak Peran Agama..., hlm. 71-72.

${ }^{50}$ A. Sunarko, “Agama di Ruang ...", hlm. 7.
} 
berada dalam ruang publik formal harus berusaha membantu menerjemahkannya argumen religius yang masuk. ${ }^{51}$

Di Indonesia, tantangan nyata dalam melakukan diskursus agama adalah fundamentalisme agama. Di dalam ruang publik informal, kerap terjadi hasutan bagi warga religius untuk bersikap tertutup terhadap kebenaran agama lain. Kita pun semakin sulit menemukan peserta diskursus yang mau bersikap rasional. Namun diskursus agama masih mungkin diterapkan di Indonesia karena masih ada pihak-pihak yang memegang prinsip rasionalitas, seperti akademisi yang rasional dan Nahdlatul Ulama (NU) sebagai penganut aliran Islam moderat.

Pemikiran Habermas mengenai diskursus agama dalam ruang publik tidak menyediakan prosedur praktis tetapi lebih merupakan kerangka berpikir. Pemikirannya tersebut bukanlah hal yang mudah untuk diterapkan di Indonesia. Namun, Indonesia terbantu menerapkannya karena terdapat dua unsur dalam Pancasila yang relevan dengan ide Habermas. Akhirnya, perjuangan mewujudkan diskursus agama dalam ruang publik secara ideal masih merupakan perjuangan terus-menerus.

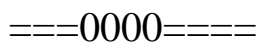

${ }^{51}$ Gusti A. B. Menoh, Agama dalam..., hlm. 188; bdk. A. Sunarko, “Agama di Ruang ...”, hlm. 12. 
- Lea Agung Srie Gunawan \& Nathania Chris Maranatha Bangun. Diskurs Agama dalam Ruang Publik

\section{DAFTAR PUSTAKA}

\section{Sumber Utama}

Habermas, Jürgen. Between Naturalism and Religion. USA: Polity Press, 2008.

------. "Basis Prapolitis Sebuah Negara Hukum yang Demokratis?", dalam Dialektika Sekularisasi. Judul asli: Vorpolitische Grundlagen des demokratischen Rechtsstaates?. Diterjemahkan oleh Paul Budi Kleden. Yogyakarta: Lamalera, 2010, hlm. 1-28.

------. "Hal-hal yang Diakui oleh Filsuf Non-Religius tentang Tuhan", dalam Giancarlo Bosetti (ed.). Iman Melawan Nalar. Diterjemahkan oleh Rene Capovin. Yogyakarta: Kanisius, 2013. hlm. 37-59.

------. "Religion in the Public Sphere", dalam European Journal of Philosophy, 14/1 (Januari 2006), hlm. 1-25.

------. Ruang Publik: Sebuah Kajian Tentang Kategori Masyarakat Borjuis (Judul asli: The Structural Transformation of the Public Sphere: An Inquiry into a Category of Bourgeois Society). Diterjemahkan oleh Yudi Santoso. Yogyakarta: Kreasi Wacana, 2008.

\section{Sumber Pendukung}

Aprianto, Anton et al. "Jam-Jam yang Mencekam", dalam Tempo (Jakarta), 7-11 November 2016, hlm. 33-35.

Bertens, K. Filsafat Barat Abad XX. Jakarta: Gramedia, 1983.

Bosetti, Giancarlo. "Pemikiran untuk Mencari Titik Temu dalam Zaman Pascasekular", dalam Giancarlo Bosetti (ed.). Iman Melawan 
Nalar. Diterjemahkan oleh Rene Capovin. Yogyakarta: Kanisius, 2013, hlm. 5-36.

Calhoun, Craig. "Religion, Secularism, and Public Reason", dalam The Holberg Prize Seminar 2005: Religion on the Public Sphere. (2005), hlm. 64-79.

Costa, Andre. Habermas on Religion in the Public Sphere: A PostSecular Conservative Critique. Canada: Trinity Western University, 2015.

Edgar, Andrew. Habermas: The Key Concepts. USA: Routledge, 2006.

-------. The Philosophy of Habermas. British: Acumen Publishing, 2005.

Finlayson, James Gordon. Habermas: A Very Short Introduction. United States: Oxford University Press, 2005.

Gora, Redemptus B. "Melacak Peran Agama dalam Ruang Publik", dalam Logos. Vol. 16 (Januari 2019), hlm. 60-72.

Habermas, Jürgen. Between Facts and Norms. Cambridge: MIT Press, 1996.

-------. "Notes on a Post-Secular Society", dalam New Perspectives Quarterly. (April 2008), hlm. 16-29.

------. Religion and Rationality: Essays on Reason, God, and Modernity. German: Polity Press, 2002.

-------. The Theory of Communicative Action: Volume 1. Boston: Bacon Press, 1984.

------. The Theory of Communicative Action: Voume 2. Boston: Bacon Press: 1987. 
_Lea Agung Srie Gunaman \& Nathania Chris Maranatha Bangun. Diskurs Agama dalam Ruang Publik

-------. Moral Consciousness and Communicative Action. United Kingdom: Polity Press, 1990.

------. "The Political", dalam The Power of Religion in the Public Sphere. New York: Columbia University Press, 2011, hlm. 15-33.

Habermas, Jürgen - Taylor, Charles. "Dialogue", dalam The Power of Religion in the Public Sphere. New York: Columbia University Press, 2011, hlm. 60-69.

Habermas, Jürgen et al. "Concluding Discussion", dalam The Power of Religion in the Public Sphere. New York: Columbia University Press, 2011, hlm. 109-117.

Hardiman, F. Budi. Demokrasi Deliberatif. Yogyakarta: Kanisius, 2009.

-------. "Demokrasi Deliberatif: Model untuk Indonesia PascaSoeharto?", dalam Basis, (November-Desember 2004), hlm. 1421.

------. Filsafat Modern. Jakarta: PT Gramedia Pustaka Utama, 2004.

Menuju Masyarakat Komunikatif. Yogyakarta: Kanisius, 2019.

Ingram, David. Habermas: Introduction and Analysis. London: Cornell University Press, 2010.

Juliawan, B. Hari. "Ruang Publik Habermas: Solidaritas Tanpa Intimitas", dalam Basis. (November-Desember 2004), hlm. 32-39.

Kleden, Ignas. "Masyarakat Post-Sekular: Tuntutan Aktualisasi Akal dan Iman", dalam Basis. No. 09-10 (2010), hlm 4-11.

Kleden, Paul Budi. "Ratzinger tentang Tema Politik", dalam Paul Budi Kleden (ed.). Dialektika Sekularisasi. Judul asli: Vorpolitische Grundlagen des demokratischen Rechtsstaates?, Diterjemahkan 
oleh Paul Budi Kleden. Yogyakarta: Lamalera, 2010, hlm. 129252.

Latif, Yudi. Negara Paripurna: Historisitas, Rasionalitas, dan aktualitas Pancasila. Jakarta: Gramedia Pustaka Utama, 2011.

Mage, Bryan. Kisah tentang Filsafat. Yogyakarta: Kanisius, 2008.

Magnis-Suseno, Franz. Filsafat sebagai Ilmu Kritis. Yogyakarta: Kanisius, 2006.

------- 12 Tokoh Etika Abad Ke-20. Yogyakarta: Kanisius, 2004.

-------. “75 Tahun Jürgen Habermas”, dalam Basis, (November-Desember 2004), hlm. 4-13.

Mendieta, Eduardo. "Introduction", dalam The Power of Religion in the Public Sphere. New York: Columbia University Press, 2011, hlm. $1-14$.

Menoh, Gusti A. B. Agama dalam Ruang Publik. Yogyakarta: Kanisius, 2018.

Nurhasim, Ahmad et al. "Dari Pulau Seribu hingga ke Twitter", dalam Tempo, (7-11 November 2016), hlm. 36-37.

Ratzinger, Joseph. "Nalar dan Iman Pertukaran Timbal Balik", dalam Iman Melawan Nalar. Yogyakarta: Kanisius, 2013, hlm. 68-69.

Reder, Michael. "Habermas and Religion", dalam An Awareness of What is Missing: Faith and Reason in a Post-Secular Age. USA: Polity Press, 2010, hlm. 1-14.

-------. "How far can faith and reason be distinguished", dalam An Awareness of What is Missing: Faith and Reason in a PostSecular Age. USA: Polity Press, 2010, hlm. 36-50. 
Schmidt, Josef. "A Dialogue in Which There Can Only be Winners" dalam An Awareness of What is Missing: Faith and Reason in a Post-Secular Age. USA: Polity Press, 2010, hlm. 59-71.

Sunarko, Adrianus. "Agama di Ruang Publik Demokratis Indonesia", dalam Basis, No. 03-04 (Mei 2013), hlm. 4-15.

------. "Berteologi bagi Agama di Zaman Post-Sekular", dalam Diskursus, Vol. 15 (April 2016), hlm. 23-42.

-------. "Dialog Teologis dengan Jürgen Habermas", dalam Paul Budi Kleden (ed.). Dialektika Sekularisasi. Yogyakarta: Lamalera, 2010, hlm. 57-120.

Portier, Philippe. "Religion and Democracy in the Thought of Jürgen Habermas", dalam Springer Science and Business Media, (2011), hlm. 426-432.

Pradja, Juhaya S. Aliran-aliran Filsafat dari Rasionalisme hingga Sekularisme. Bandung: Alva Gracia, 1987.

Ummah, Sun Choirol. "Dialektika Agama dan Negara dalam Karya Jurgen Habermas", dalam Humanika, Vol. 16 (September 2016), hlm. 79-91.

Vatter, Miguel. "Habermas between Athens and Jerusalem", dalam Interpretation Vol. 38 (2011), hlm. 243-260.

Viktorahadi, Bhanu. "Kritik Jürgen Habermas terhadap Peran dan Fungsi Agama dalam Masyarakat Modern", dalam Jurnal Theologia, Vol. 28 (2017), hlm. 273-298. 


\section{Kamus dan Ensiklopedi}

Bagus, Lorens. Kamus Filsafat. Jakarta: PT Gramedia Pustaka Utama, 1996.

Clark. "Hitler Youth", dalam The New Encyclopadia Britannica, Vol. 5. Chicago: Encyclopædia Britannica, inc., 1986, hlm. 950.

Ekayanti. "Hitler, Adolf”, dalam Ensiklopedi Nasional Indonesia, Jilid II. Jakarta: PT Cipta Adi Pustaka, 1990, hlm. 450-452.

James. "Nürnberg Trials", dalam The New Encyclopadia Britannica, Vol. 8. Chicago: Encyclopædia Britannica, inc., 1986, hlm. 834.

Kelly. "Nazi Party", dalam The New Encyclopadia Britannica, Vol. 8. Chicago: Encyclopædia Britannica, inc., 1986, hlm. 144-146

Kevin. "World War II", dalam The New Encyclopadia Britannica, Vol. 12. Chicago: Encyclopædia Britannica, inc., 1986, hlm. 758.

Masyud. "Perang Dunia II", dalam Ensiklopedi Nasional Indonesia, Jilid VII. Jakarta: PT Cipta Adi Pustaka, 1990, hlm. 34-38.

McInnes, Neil. "Marx, Karl”, dalam The Encyclopedia of Philosophy, Volume 5 and 6. Great Britain: McMillan Inc., 1967, hlm. 172.

Pusat Bahasa Departemen Pendidikan Nasional. Kamus Besar Bahasa Indonesia (Edisi Ketiga). Jakarta: Balai Pustaka, 2008.

Routledge, Concise. Encyclopedia of Philosophy. Great Britain: TJ International Ltd, 2000.

Shadily, Hassan (ed.). Ensiklopedi Umum. Yogyakarta: Kanisius, 1993. 
_ Lea Agung Srie Gunawan \& Nathania Chris Maranatha Bangun. Diskurs Agama dalam Ruang Publik

Sudiyono. "Konsentrasi, Kamp", dalam Ensiklopedi Nasional Indonesia, Jilid IV. Jakarta: PT Cipta Adi Pustaka, 1990, hlm. 55.

Purwoko, Dwi. "Nazisme”, dalam Ensiklopedi Nasional Indonesia, Jilid VI. Jakarta: PT Cipta Adi Pustaka, 1990, hlm. 54-55.

\section{Internet}

BBC, What Happened on 11 September 2001?, https://www.bbc.co.uk/newsround/amp/ 14854813; diakses, 27 Agustus 2019.

CBC News, Bin Laden Claims Responsibility for 9/11, https://www.cbc.ca/news/world/bin-laden-claims-responsibilityfor-9-11-1.51365; diakses, 27 Agustus 2019.

https://www.friedenspreis-des-deutschenuchhandels.de/sixcms/media.php/1290/2001\%20Acceptance\%20 Speech\%20Juergen\%20Habermas.pdf; diakses, 20 November 2019.

https://www.bbc.com/indonesia/laporan_khusus/2011/09/110908_kronol ogiseptember, diakses 1 Desember 2019.

https://kbbi.web.id/dialog, diakses pada 5 Maret 2020.

https://kbbi.web.id/debat, diakses pada 5 Maret 2020.

Indonesia.Go.Id., Agama, https://www.indonesia.go.id/profil/agama; diakses 15 Maret 2020 